\title{
PENGEMBANGAN GAME EDUKASI "AKSARA JAWA" BERBASIS UNITY UNTUK SISWA KELAS 3 SDN MULYOARJO 3 LAWANG
}

\author{
Wanda Ramansyah \\ Universitas Trunojoyo Madura \\ Bangkalan, Indonesia \\ wandaramansyah@ hotmail.com
}

\begin{abstract}
Abstrak
Mata pelajaran Bahasa Jawa adalah mata pelajaran yang wajib diikuti oleh siswa Kelas 3 di Sekolah Dasar. Dalam mata pelajaran Bahasa Jawa ini terdapat bab yang membahas tentang bentuk huruf Aksara Jawa. Dilihat dari karakter pembelajarannya maka materi dalam mata pelajaran ini banyak membahas tentang hafalan huruf Aksara Jawa. Permasalahan muncul karena belajar menggunakan papan tulis, buku dan poster dirasa kurang baik untuk proses penghafalan siswa. Perlu media atau strategi inovatif untuk mempermudah proses menghafal siswa. Game edukasi akan menyelesaikan permasalahan ini dengan menyediakan materi Aksara Jawa yang disajikan melalui permainan. Dengan adanya game edukasi ini maka siswa akan lebih mudah dan cepat serta menyenangkan saat mereka menghafal bentuk huruf Aksara Jawa.
\end{abstract}

Kata Kunci: Game, Edukasi, Aksara Jawa

\begin{abstract}
Java Language subject is a subject that must be followed by the third grade students in an elementary school. In the Java language 's subjects are the chapter on Java script typeface. Judging from the character of learning the material in these subjects much about memorizing letters Java script. Problems arise because learning to use the blackboard, books and posters is less good for the student memorization process. Keep in media or innovative strategy to facilitate the student memorization process. Education game will solve this problem by providing a Java script material presented through the game. With the game this education the students will be easier and faster as well as fun when they memorize Java script typeface.
\end{abstract}

Keywords : Game, Education, Java Script 


\section{PENDAHULUAN}

Di dunia ini terdapat berbagai jenis bahasa yang dipakai untuk berkomunikasi dalam kehidupan sehari-hari. Dari bermacam jenis bahasa tersebut diketahui bahwa Bahasa Jawa menempati urutan ke 11 di dunia dalam hal banyaknya jumlah penutur. Kebanggaan ini diwujudkan pendidikan di Indonesia dengan memasukkan Mata Pelajaran Bahasa Jawa sebagai mata pelajaran wajib yang harus dikuasai siswa khususnya di Pulau Jawa mulai dari jenjang SD sebagai bentuk kecintaan dan pelestarian Bahasa Jawa.

Mata Pelajaran Bahasa Jawa mulai diberikan pada jenjang Kelas $3 \mathrm{SD}$, di mana pelajaran diawali dengan mengenal bentuk huruf Aksara Jawa. Seperti yang diketahui bahwa bentuk huruf Aksara Jawa memiliki bentuk berbeda dibandingkan bentuk huruf abjad yang biasa dilihat dan digunakan siswa. Penghafalan bentuk huruf Aksara Jawa harus dikuasai siswa karena hal tersebut merupakan kunci untuk mempelajari Bahasa Jawa sehingga mulai dini siswa harus dilatih hafal tentang bentuk huruf Aksara Jawa.

Mata Pelajaran Bahasa Jawa yang disajikan guru dalam kelas untuk penghafalan bentuk huruf Aksara Jawa kebanyakan masih konvensional. Biasanya guru menuliskan bentuk-bentuk huruf Aksara Jawa di papan tulis dilanjutkan siswa menulis di buku tulis dilanjutkan dengan membaca huruf bersamasama. Ada juga guru yang membawa poster berisi huruf Aksara Jawa kemudian ditempel di papan tulis sambil menerangkan kepada siswa.

Metode penghafalan tersebut dirasakan kurang efektif karena tidak dilakukan dengan cara yang menyenangkan bagi siswa. Seharusnya ada metode penghafalan bentuk huruf Akasara Jawa yang lebih menyenangkan yang membuat proses penghafalan lebih efektif, efisien, dan menarik. Agar menyenangkan tentu saja proses penghafalan tersebut harus sesuai dengan karakteristik siswa SD.
Perkembangan teknologi informasi dan komunikasi yang sangat pesat mendorong berbagai lembaga pendidikan memanfaatkan kemajuan teknologi tersebut guna meningkatkan mutu pembelajaran. Media (selain guru) yang biasanya hanya menyajikan komunikasi satu arah, saat ini oleh perkembangan teknologi dapat dimodifikasi menjadi media yang menyajikan pembelajaran dua arah yang disebut dengan pembelajaran interaktif. Di mana salah satu media pembelajaran interaktif yang sedang naik daun saat ini adalah game edukasi. Game edukasi menjadi perhatian kalangan pendidikan karena media ini dapat menyajikan pembelajaran dengan proses yang menyenangkan.

Game merupakan salah satu media yang digunakanuntuk menyampaikan suatu pesan kepada orang umum dalam bentuk permainan yang dapat menghibur. Perkembangan game saat ini mengarah ke dalam berapa bagian yaitu console game dan computer game. Tipetipe game yang ada pada saat ini adalah berupa real time strategy, role play game, first person shooter. Saat ini game menjadi salah satu bagian dalam kehidupan masyarakat modern dari anak kecil sampai dengan orang dewasa. Berdasarkan kajian di atas maka dengan banyaknya orang yang memainkan game maka pengembangan game (game development) mulai mengarah ke dalam industri game edukasi. Hal ini dimaksudkan selain mendapatkan hiburan dalam bermain game, pemain juga mendapatkan nilai tambah yaitu pengetahuan.

Kondisi ideal yang diharapkan dalam pembelajaran Mata Pelajaran Bahasa Jawa adalah tersedianya media pembelajaran berupa game edukasi yang menyenangkan dan dapat memudahkan siswa untuk belajar sekaligus dapat memotivasi dan meningkatkan daya tarik siswa untuk belajar. Namun kondisi riil yang dihadapi saat ini adalah masih kurang dan terbatasnya media yang digunakan guru dalam pembelajaran Mata Pelajaran Bahasa Jawa. 
Jika guru hanya menggunakan papan tulis, buku tematik, atau poster saja maka siswa akan kesulitan dan kurang tertarik untuk menghafal bentuk huruf Aksara Jawa. Kesenjangan antara kondisi ideal dan kondisi riil ini harus segera diatasi agar memudahkan siswa dalam belajar Bahasa Jawa, motivasi dan daya tarik peserta didik dalam belajar dapat meningkat, dan nilai hasil belajar siswa bisa mencapai nilai maksimal.

Keterbatasan papan tulis, buku tematik, atau poster untuk memfasilitasi siswa dalam belajar Mata Pelajaran Bahasa Jawa harus segera diatasi dengan menggunakan game edukasi "Aksara Jawa". Dalam game edukasi "Aksara Jawa" ini akan disajikan pembelajaran melalui permainan yang menarik sekaligus sanggup memudahkan siswa menghafal bentuk huruf Aksara Jawa, hal itu dikarenakan dalam game edukasi ini menyajikan permainan yang berkaitan dengan bentuk huruf aksara jawa yang harus dimainkan siswa.

Penelitian sebelumnya pada tahun 2013 dengan judul Pengembangan Game Edukasi Visual Novel Berbasis Pembangunan Karakter Pada Materi Pelestarian Lingkungan oleh Arif Rahman Hikam, Nana Kariada, dan Kukuh Santosa Jurusan Biologi FMIPA Universitas Negeri Semarang menemukan hasil bahwa media game edukasi mendapatkan tanggapan layak dari siswa dan dapat berpengaruh positif terhadap hasil belajar siswa. Penelitian oleh Dony Novaliendry dalam Jurnal Teknologi Informasi dan Pendidikan tahun 2013 dengan judul Aplikasi Game Geografi Berbasis Multimedia Interaktif (Studi Kasus Siswa Kelas IX SMPN 1 Rao) menemukan hasil bahwa game edukasi dapat meningkatkan kreativitas siswa. Sedangkan Wanda Ramansyah dalam peneltian berjudul Pengembangan Education Game (Edugame) Berbasis Android Pada Mata Pelajaran Bahasa Inggris Untuk Peserta Didik Sekolah Dasar mendapatkan hasil bahwa produk game edukasiberada pada kualifikasi "tinggi" atau "layak" dalam efektifitas, efisiensi, dan daya tarik dan tidak memerlukan revisi.

Menurut Retno (2011: 1) "Game berasal dari kata bahasa Inggris yang memiliki arti dasar permainan. Permainan dalam hal ini merujuk pada pengertian kelincahan intelektual intellectual playability)". Game juga bisa diartikan sebagai arena keputusan dan aksi pemainnya, ada target-target yang ingin dicapai pemainnya. Kelincahan intelektual pada tingkat tertentu merupakan ukuran sejauh mana game itu menarik untuk dimainkan secara maksimal. Game juga secara nyata mempertajam daya analisis para penggunanya untuk mengolah informasi dan mengambil keputusan cepat yang jitu.

Penerapan game edukasi bermula dari perkembangan video game yang sangat pesat dan menjadikannya sebagai media efektif yang interaktif dan banyak dikembangkan di perindustrian. Melihat kepopuleran game tersebut, para pendidik berpikir bahwa mereka mempunyai kesempatan yang baik untuk menggunakan komponen rancangan game dan menerapkannya pada kurikulum dengan penggunaan media pembelajaran berbasis game. Game edukasi adalah permainan yang telah dirancang khusus untuk mengajarkan siswa (user) suatu pembelajaran tertentu, pengembangan konsep dan pemahaman dan membimbing mereka dalam melatih kemampuan mereka, serta memotivasi mereka untuk memainkannya Menurut Hurd dan Jenuings (dalam Khairunnisa: 12-13), perancangan game edukasi yang baik haruslah memenuhi kriteria dari game edukasi itu sendiri.

Berikut ini adalah beberapa kriteria dari sebuah game edukasi, yaitu:

1. Nilai Keseluruhan (OverallValue)

Nilai keseluruhan dari suatugame terpusat pada desaindan panjang durasi game.Aplikasi ini dibangun dengandesain yang menarik daninteraktif.

2. Dapat Digunakan (Usability) 
Mudah digunakan dan diaksesadalah poin penting bagipembuat game. Apliksi inimerancang sistem denganinterface yang user friendlysehingga user dengan mudahdapat mengakses aplikasi.

3. Keakuratan (Accuracy)

Keakuratan diartikan sebagaibagaimana kesuksesan modelatau gambaran sebuah gamedapat dituangkan ke dalampercobaan atauperancangannya.Perancangan aplikasi ini harussesuai dengan model gamepada tahap perencanaan.

4. Kesesuaian (Appropriateness)

Kesesuaian dapat diartikanbagaimana isi dan desaingame dapat diadaptasikanterhadap keperluan userdengan baik. Aplikasi inimenyediakan menu dan fituryang diperlukan user untukmembantu pemahaman userdalammenggunakan aplikasi.

5. Relevan (Relevance)

Relevan artinya dapatmengaplikasikan isi game ketarget user. Agar dapat relevanterhadap user, sistem harusmembimbing mereka dalampencapaian tujuanpembelajaran. Karena aplikasiini ditujukan untuk siswa makadesain antarmuka harussesuai dengan nuansa siswa,yaitu menampilkan warna-warnayang ceria.

6. Objektifitas (Objectives)

Objektifitas menentukan tujuanuser dan kriteria darikesuksesan atau kegagalan.Dalam aplikas ini objektivitasadalah usaha untukmempelajari hasil daripermainan.

7. Umpan Balik (Feedback)

Untuk membantu pemahamanuser bahwa permainan(performance) mereka sesuaidengan objek game atau tidak,feedback harus disediakan.Aplikasi ini menyajikan animasidan efek suara yangmengindikasikan kesuksesanatau kegagalan permainan.

Menurut Samuel (2010: 53),dampak positif yang dihasilkan olehgame edukasi adalah:

1. Memainkan game membuatanak mengenal teknologikomputer.

2. Game dapat memberikanpelajaran dalam hal mengikutipengajaran dan aturan.

3. Beberapa game menyediakanlatihan untuk pemecahanmasalah dan logika.

4. Game menyediakan latihanpenggunaan syaraf motorikdan spatial skill.

5. Game menjadi saranakeakraban dan interaksi akrabantara orangtua dan anakketika bermain bersama.

6. Game mengenalkan teknologidan berbagai fiturnya.

7. Beberapa game mampumenyediakan saranapenyembuhan untuk pasientertentu.

8. Game menghibur danmenyenangkan.

Dengan pemaparan di atas maka perlu diciptakan game edukasi "Aksara Jawa" menggunakan model pengembangan Kemp dan Dayton pada Mata Pelajaran Bahasa Jawa. Game edukasi tersebut akan mampu mengatasi kesulitan siswa dalam menghafal bentuk huruf dan belajar Aksara Jawa dibandingkan dengan pembelajaran yang hanya menggunakan papan tulis, buku tematik, atau poster saja.

Tujuan pengembangan ini adalah untuk mengatasi permasalahan belajar sisswa dengan menciptakan media belajar berupa game edukasi pada pembelajaran Mata Pelajaran Bahasa Jawa yang bertujuan untuk membantu siswa Kelas 3 Sekolah Dasar untuk menghafal bentuk-bentuk huruf Aksara Jawa dengan cara yang menyenangkan. 


\section{METODE PENELITIAN}

Jenis penelitian ini adalah penelitian pengembangan karena mengembangkan game edukasi pada Mata Pelajaran Bahasa Jawa. Penelitian pengembangan ini dilaksanakan untuk menghasilkan suatu game edukasi yang selanjutnya diujicobakan efektifitas, efisiensi, dan daya tarik dari game edukasi tersebut.

Model pengembangan game edukasi ini dapat menggunakan model Kemp dan Dayton,

di mana langkah-langkah dalam pengembangan media pembelajaran harus melalui beberapa tahap, yaitu menentukan: (1) ide atau tujuan umum pembelajaran, (2) tujuan khusus pembelajaran, (3) karakteristik audiens, (4) isi materi (content outline), (5) treatment, (6) storyboard, (7) naskah (script), (8) developing, editing, and mixing, dan (9) testing and revising. Khusus pada tahap developing, editing, and mixing di atas pengembang menggunakan program komputer yaitu Unity.

Pada dasarnya kegiatan uji coba produk pengembangan dilaksanakan sebagai langkah evaluasi formatif yang terdiri atas uji coba perorangan, uji coba kelompok kecil, dan uji coba kelompok besar (lapangan). Di mana sasaran uji coba di seluruh kegiatan uji coba tersebut adalah siswa Kelas 3 di SDN Mulyoarjo 3 Lawang. Subjek uji coba adalah sasaran pengguna produk pengembangan yaitu siswa Kelas 3 di SDN Mulyoarjo 3 Lawang dengan jumlah 36siswa. Dalam uji coba ini sasaran siswa yang dibutuhkan adalah 3 peserta didik untuk uji coba perorangan, 9 peserta didik untuk uji coba kelompok kecil, dan 24 peserta didik untuk uji kelompok besar (uji lapangan).

HASIL PENELITIAN DAN

\section{PEMBAHASAN}

Hasil penelitian pada pengembangan ini adalah berupa game edukasi yang berfungsi sebagai media dalam pembelajaran Aksara Jawa bagi siswa Kelas 3 SD. Adapun hasil pengembangan yang menggunakan Unity ini dapat ditunjukkan dari gambar berikut ini: 

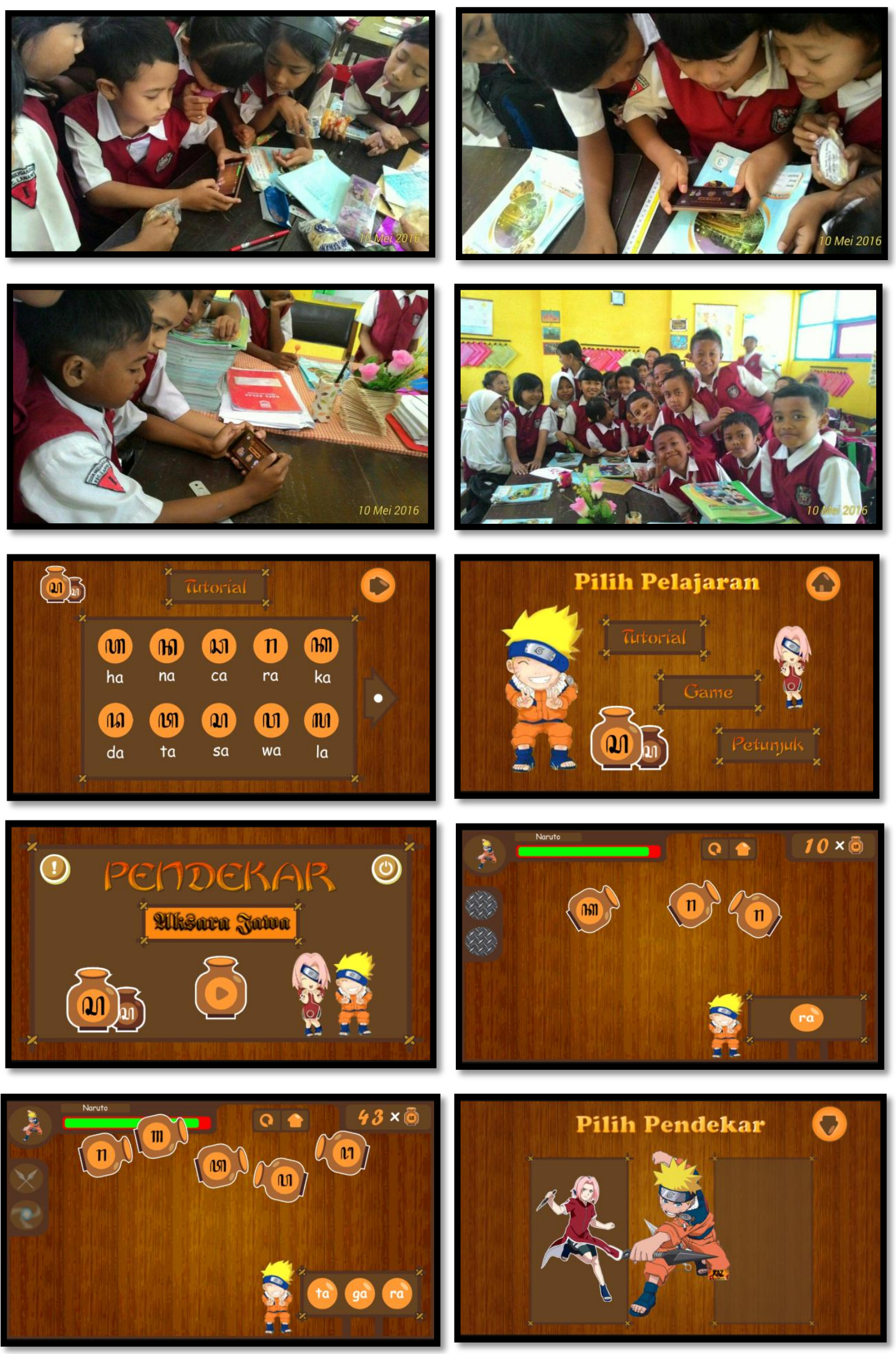

Gambar 1. Beberapa screenshot dalam game edukasi 
Dari pengembangan yang telah diciptakan maka dilakukan uji coba produk tersebut pada siswa Kelas 3 di SDN Mulyoarjo 3 Lawanguntuk mengetahui efektifitas, efisiensi, dan daya tarik media. Setelah angket terkumpul maka akan dihitung prosentase dari tiap-tiap butir pertanyaan pada angket dengan rumus menurut Komang I. Sudarman (2006) adalah sebagai berikut:

Keterangan:

$$
\text { Prosentase jawaban }=\frac{\mathrm{F}}{\mathrm{N}} \times 100 \%
$$

$\mathrm{F}=$ Frekuensi subjek yang memilih alternatif jawaban

$\mathrm{N}=$ Jumlah keseluruhan subjek (total responden)

Pemberian makna dan pengambilan keputusan tentang kualitas produk media pembelajaran interaktif berbasis komputer ini akan menggunakan konversi tingkat pencapaian dengan skala seperti tabel di bawah ini:

Tabel 1. Konversi Tingkat Pencapaian dan Kualifikasi

\begin{tabular}{|c|c|}
\hline Tingkat Pencapaian & Kualifikasi \\
\hline $90 \%-100 \%$ & Sangat tinggi, tidak perlu revisi \\
\hline $75 \%-89 \%$ & Tinggi, tidak perlu revisi \\
\hline $65 \%-74 \%$ & Cukup tinggi, perlu revisi \\
\hline $55 \%-64 \%$ & Kurang tinggi, perlu revisi \\
\hline $0 \%-54 \%$ & Sangat kurang tinggi, revisi besar \\
\hline
\end{tabular}

Hasil analisis data ini akan digunakan untuk merevisi produk pengembangan, mengkaji produk, dan memberikan saran pemanfaatan serta pengembangan lebih lanjut.

Dari uji coba produk baik secara perorangan, kelompok kecil, dan kelompok besar didapat data sebagai berikut:

Tabel 2. Komponen-Komponen yang Dinilai Pada Uji Coba Perorangan

\begin{tabular}{|c|c|c|c|c|c|}
\hline No. & Komponen yang dinilai & $\begin{array}{l}\text { Skor dari } \\
\text { responden }\end{array}$ & $\begin{array}{l}\text { Jumlah }\left(\sum\right) \\
\text { skor }\end{array}$ & $\begin{array}{c}\text { Rata-rata skor } \\
\left(\sum \text { skor/responden }\right. \\
)\end{array}$ & Presentase (\%) \\
\hline 1. & $\begin{array}{l}\text { Kemampuan game edukasi } \\
\text { mampu menyampaikan materi- } \\
\text { materi pelajaran Aksara Jawa. }\end{array}$ & 444 & 12 & 4 & $80 \%$ \\
\hline 2. & $\begin{array}{l}\text { Kejelasan isi materi-materi } \\
\text { pada game edukasi. }\end{array}$ & 445 & 13 & 4,333333 & $86,66667 \%$ \\
\hline 3. & $\begin{array}{l}\text { Kejelasan animasi pada game } \\
\text { edukasi. }\end{array}$ & 434 & 11 & 3,666667 & $73,33333 \%$ \\
\hline 4. & $\begin{array}{l}\text { Kejelasan teks pada game } \\
\text { edukasi. }\end{array}$ & 544 & 13 & 4,333333 & $86,66667 \%$ \\
\hline 5. & $\begin{array}{l}\text { Kemampuan game edukasi } \\
\text { untuk memudahkan siswa } \\
\text { dalam belajar. }\end{array}$ & 444 & 12 & 4 & $80 \%$ \\
\hline 6. & $\begin{array}{l}\text { Kemudahan saat } \\
\text { mengoperasikan atau } \\
\text { menjalankan game edukasi. }\end{array}$ & 445 & 13 & 4,333333 & $86,66667 \%$ \\
\hline 7. & $\begin{array}{l}\text { Tampilan visual (gambar, } \\
\text { video, atau animasi) dalam } \\
\text { memudahkan siswa saat belajar }\end{array}$ & 344 & 11 & 3,666667 & $73,33333 \%$ \\
\hline
\end{tabular}




\begin{tabular}{|c|l|c|c|c|c|}
\hline 8. & $\begin{array}{l}\text { Daya tarik audio (musik, efek } \\
\text { suara, atau narasi) dalam game } \\
\text { edukasi }\end{array}$ & 434 & 11 & 3,666667 & $73,33333 \%$ \\
\hline 9. & $\begin{array}{l}\text { Tampilan teks dan bentuk } \\
\text { tulisan (font) dalam game } \\
\text { edukasi }\end{array}$ & 445 & 13 & 4,333333 & $86,66667 \%$ \\
\hline 10. & $\begin{array}{l}\text { Kombinasi, tatanan, dan } \\
\text { pemilihan warna dalam game } \\
\text { edukasi }\end{array}$ & 444 & 12 & 4 & $80 \%$ \\
\hline \multicolumn{2}{|l|}{ Rata-rata prosentase keseluruhan } & $\mathbf{8 0 , 6 7 \%}$ \\
\hline
\end{tabular}

Tabel 3. Komponen-Komponen yang Dinilai pada Uji Coba Kelompok Kecil

\begin{tabular}{|c|c|c|c|c|c|}
\hline No. & Komponen yang dinilai & $\begin{array}{l}\text { Skor dari } \\
\text { responden }\end{array}$ & $\begin{array}{l}\text { Jumlah }\left(\sum\right) \\
\text { skor }\end{array}$ & \begin{tabular}{|c|} 
Rata-rata skor \\
$\left(\sum\right.$ skor/responden \\
)
\end{tabular} & Presentase $(\%)$ \\
\hline 1. & $\begin{array}{l}\text { Kemampuan game edukasi } \\
\text { mampu menyampaikan materi- } \\
\text { materi pelajaran Aksara Jawa. }\end{array}$ & $\begin{array}{c}53554534 \\
3\end{array}$ & 37 & 4,111111 & $82,22222 \%$ \\
\hline 2. & $\begin{array}{l}\text { Kejelasan isi materi-materi } \\
\text { pada game edukasi. }\end{array}$ & $\begin{array}{c}53444535 \\
5\end{array}$ & 38 & 4,222222 & $84,44444 \%$ \\
\hline 3. & $\begin{array}{l}\text { Kejelasan animasi pada game } \\
\text { edukasi. }\end{array}$ & $\begin{array}{c}44444544 \\
4\end{array}$ & 37 & 4,111111 & $82,22222 \%$ \\
\hline 4. & $\begin{array}{l}\text { Kejelasan teks pada game } \\
\text { edukasi. }\end{array}$ & $\begin{array}{c}44454444 \\
4\end{array}$ & 37 & 4,111111 & $82,22222 \%$ \\
\hline 5. & $\begin{array}{l}\text { Kemampuan game edukasi } \\
\text { untuk memudahkan siswa } \\
\text { dalam belajar. }\end{array}$ & $\begin{array}{c}43354554 \\
5\end{array}$ & 38 & 4,222222 & $84,44444 \%$ \\
\hline 6. & $\begin{array}{l}\text { Kemudahan saat } \\
\text { mengoperasikan atau } \\
\text { menjalankan game edukasi. }\end{array}$ & $\begin{array}{c}44443554 \\
4\end{array}$ & 37 & 4,111111 & $82,22222 \%$ \\
\hline 7. & $\begin{array}{l}\text { Tampilan visual (gambar, } \\
\text { video, atau animasi) dalam } \\
\text { memudahkan siswa saat belajar }\end{array}$ & $\begin{array}{c}44444454 \\
5\end{array}$ & 38 & 4,222222 & $84,44444 \%$ \\
\hline 8. & $\begin{array}{l}\text { Daya tarik audio (musik, efek } \\
\text { suara, atau narasi) dalam game } \\
\text { edukasi }\end{array}$ & $\begin{array}{c}54334545 \\
5\end{array}$ & 38 & 4,222222 & $84,44444 \%$ \\
\hline 9. & $\begin{array}{l}\text { Tampilan teks dan bentuk } \\
\text { tulisan (font) dalam game } \\
\text { edukasi }\end{array}$ & $\begin{array}{c}44454545 \\
4\end{array}$ & 39 & 4,333333 & $86,66667 \%$ \\
\hline 10. & $\begin{array}{l}\text { Kombinasi, tatanan, dan } \\
\text { pemilihan warna dalam game } \\
\text { edukasi }\end{array}$ & $\begin{array}{c}34554544 \\
5\end{array}$ & 39 & 4,333333 & $86,66667 \%$ \\
\hline \multicolumn{5}{|c|}{ Rata-rata prosentase keseluruhan } & $84 \%$ \\
\hline
\end{tabular}


Tabel 4. Komponen-Komponen yang Dinilai pada Uji Coba Kelompok Besar

\begin{tabular}{|c|c|c|c|c|c|}
\hline No. & Komponen yang dinilai & $\begin{array}{l}\text { Skor dari } \\
\text { responden }\end{array}$ & $\begin{array}{c}\text { Jumlah }\left(\sum\right) \\
\text { skor }\end{array}$ & $\begin{array}{c}\text { Rata-rata skor } \\
\left(\sum \text { skor/responden }\right. \\
)\end{array}$ & Presentase $(\%)$ \\
\hline 1. & $\begin{array}{l}\text { Kemampuan game edukasi } \\
\text { mampu menyampaikan materi- } \\
\text { materi pelajaran Aksara Jawa. }\end{array}$ & $\begin{array}{l}45454555 \\
54555555 \\
44555555\end{array}$ & 129 & 4,8 & $96 \%$ \\
\hline 2. & $\begin{array}{l}\text { Kejelasan isi materi-materi } \\
\text { pada game edukasi. }\end{array}$ & $\begin{array}{l}54454544 \\
44544454 \\
54444445\end{array}$ & 117 & 4,3 & $86 \%$ \\
\hline 3. & $\begin{array}{l}\text { Kejelasan animasi pada game } \\
\text { edukasi. }\end{array}$ & $\begin{array}{l}44454544 \\
54544454 \\
54444445\end{array}$ & 117 & 4,3 & $86 \%$ \\
\hline 4. & $\begin{array}{l}\text { Kejelasan teks pada game } \\
\text { edukasi. }\end{array}$ & $\begin{array}{l}45454544 \\
54544444 \\
54444445\end{array}$ & 117 & 4,3 & $86 \%$ \\
\hline 5. & $\begin{array}{l}\text { Kemampuan game edukasi } \\
\text { untuk memudahkan siswa } \\
\text { dalam belajar. }\end{array}$ & $\begin{array}{l}44454554 \\
54544454 \\
44444445\end{array}$ & 117 & 4,3 & $86 \%$ \\
\hline 6. & $\begin{array}{l}\text { Kemudahan saat } \\
\text { mengoperasikan atau } \\
\text { menjalankan game edukasi. }\end{array}$ & $\begin{array}{l}44544544 \\
54544454 \\
54444445\end{array}$ & 117 & 4,3 & $86 \%$ \\
\hline 7. & $\begin{array}{l}\text { Tampilan visual (gambar, } \\
\text { video, atau animasi) dalam } \\
\text { memudahkan siswa saat belajar }\end{array}$ & $\begin{array}{l}54454444 \\
54544454 \\
54444445\end{array}$ & 117 & 4,3 & $86 \%$ \\
\hline 8. & $\begin{array}{l}\text { Daya tarik audio (musik, efek } \\
\text { suara, atau narasi) dalam game } \\
\text { edukasi }\end{array}$ & $\begin{array}{l}45454555 \\
55555555 \\
44555455\end{array}$ & 129 & 4,8 & $96 \%$ \\
\hline 9. & $\begin{array}{l}\text { Tampilan teks dan bentuk } \\
\text { tulisan (font) dalam game } \\
\text { edukasi }\end{array}$ & $\begin{array}{l}54454544 \\
54544454 \\
54444445\end{array}$ & 117 & 4,3 & $86 \%$ \\
\hline 10. & $\begin{array}{l}\text { Kombinasi, tatanan, dan } \\
\text { pemilihan warna dalam game } \\
\text { edukasi }\end{array}$ & $\begin{array}{l}44454544 \\
54544454 \\
54444445\end{array}$ & 117 & 4,3 & $86 \%$ \\
\hline \multicolumn{5}{|c|}{ Rata-rata prosentase keseluruhan } & $88 \%$ \\
\hline
\end{tabular}


Dari data yang dihasilkan saat uji coba perorangan yang terdiri dari tiga siswa Kelas 3 SDN Mulyoarjo 3 Lawang diketahui bahwa rata-rata prosentase secara keseluruhan mengenai kualitas game edukasi adalah $80,67 \%$. Hal ini menunjukkan bahwa produk game edukasi Aksara Jawa berada pada kualifikasi "tinggi" dan tidak memerlukan revisi.

Dari data yang dihasilkan saat uji coba kelompok kecil yang terdiri dari sembilan siswa Kelas 3 SDN Mulyoarjo 3 Lawang diketahui bahwa rata-rata prosentase secara keseluruhan mengenai kualitas game edukasi adalah $84 \%$. Hal ini menunjukkan bahwa produk game edukasi Aksara Jawa berada pada kualifikasi "tinggi" dan tidak memerlukan revisi.

Dari data yang dihasilkan saat uji coba kelompok besar yang terdiri dari dua puluh empat siswa Kelas 3SDN Mulyoarjo 3 Lawang diketahui bahwa rata-rata prosentase secara keseluruhan mengenai kualitas game edukasi adalah $88 \%$. Hal ini menunjukkan bahwa produk game edukasi Aksara Jawa berada pada kualifikasi "tinggi" dan tidak memerlukan revisi.

\section{KESIMPULAN DAN SARAN}

Dari hasil penelitian yang telah dilakukan pengembang, maka game edukasi Aksara Jawa ini telah berhasil diuji tingkat efektifitas, efisiensi, dan daya tariknya. Di mana dari penelitian tersebut pengembang telah mendapatkan data yang mendukung bahwa produk yang dikembangkan telah memiliki nilai efektifitas, efisiensi, dan daya tarik untuk digunakan dalam pembelajaran.

Game edukasi ini menyajikan permainan yang berkaitan dengan Bahasa Jawa khususnya bentuk-bentuk huruf Aksara Jawa. Dalam permainan ini siswa akan memilih bentuk huruf yang sesuai dengan perintah di dalam game. Di mana jika dilakukan berulang-ulang dan dengan taraf kesukaran yang meningkat maka proses penghafalan siswa terhadap
Aksara Jawa akan lebih baik. Produk pengembangan berupa game edukasi ini dapat digunakan sebagai sumber dalam meningkatkan strategi penyampaian pesan atau strategi mengajar guru agar lebih inovatif dan bermutu khususnya dalam Mata Pelajaran Bahasa Jawa.

Selain itu, instrumen-instrumen tambahan dalam game edukasi (seperti: musik, gambar, animasi, dan efek suara) dapat menarik perhatian siswa dan menghilangkan kebosanan dalam belajar, justru game edukasi ini dapat meningkatkan keinginan lebih siswa untuk belajar dan siswa ingin belajar terus menerus.

Saran pemanfaatan produk dari pengembang yang berkaitan dengan game edukasi "Aksara Jawa" berbasis Unity ini adalah sebagai berikut:

a. Guru sebaiknya menyediakan perangkat yang banyak sejumlah siswa agar siswa dapat menggunakan game edukasi ini tanpa menunggu giliran atau minimal penggunaan dalam kelompok kecil.

b. Game edukasi ini disarankan dalam kegiatan pembelajaran agar guru lebih kreatif dalam menyampaikan materi kepada siswa, menampilkan pembelajaran yang inovatif, tidak membosankan bagi siswa, dan lebih memudahkan siswa untuk menghafal bentuk huruf Aksara Jawa.

c. Game edukasi ini akan lebih maksimal dan baik manfaatnya jika guru dan siswa sudah sama-sama tahu bagaimana mengoperasikan game edukasi ini.

d. Game edukasi ini dapat digunakan sebagai media, alat, atau sarana dalam strategi penyampaian pesan pada proses pembelajaran dari seorang guru kepada siswanya yang membuat pembelajaran lebih bermakna dan menyenangkan bagi siswa. 
e. Agar lebih menantang, guru dapat mengkombinasikan game edukasi ini dengan strategi atau metode lain, seperti membuat kompetisi dan berhadiah bagi pemenang atau peraih nilai game tertinggi.

\section{DAFTAR PUSTAKA}

Anwas, Oos M. 2003. Model Inovasi ELearning Dalam Meningkatkan Mutu Pendidikan. Jurnal Teknodik: Edisi No.12/VII/Oktober/2003.

Degeng, I Nyoman, S. 1989. Teori Pembelajaran 1: Taksonomi Variabel. Malang: Universitas Negeri Malang.

Degeng, I Nyoman, S. 1990. Teori Pembelajaran 2: Terapan. Malang: Universitas Negeri Malang.

Degeng, I Nyoman, S. 1994. Teknologi Pembelajaran: Definisi dan Kawasannya Malang: Universitas Negeri Malang.

Hartanto, Antonius Aditya dan Onno W. Purbo. 2002. E-Learning berbasis PHP dan MySQL. Jakarta: Elex Media Komputindo.

Kemp, Jerrold E., dan Dayton, Deane K. 1985. Planning And Producing Instructional Media. New York: Harper \& Row Publisher Inc.

Ramansyah, Wanda. 2010. Pengembangan Multimedia Pembelajaran Interaktif Berbasis Komputer Pada Mata Diklat Dasar-Dasar Mesin. Tesis tidak diterbitkan. PPS Universitas Negeri Malang.
Retno Ayu SP. 2011. Pengertian Game, (online).

http://retnoayusp.blogspot.com/2011/03/

pengertian-game_23.html

Richard A. Schwier dan Earl R. Misanchuk. (1993). Interactive Multimedia Instruction. New Jersey : Educational Technology Publications.

Rob Phillips. (1997). The Developer's Handbooks to Interactive Multimedia: A Practice Guide for Educational Applications. London: Kogan Page Limited.

Sadiman, Arief, S. 2008. Media Pendidikan: Pengertian, Pengembangan, dan Pemanfaatannya. Jakarta: PT. Raja Grafindo Persada.

Saepudin, Asep. 2003. Penerapan Teknologi Informasi Dalam Pendidikan Masyarakat. Jurnal Teknodik: Edisi No.12/VII/Oktober/2003.

Seels, Barbara., dan Glasgow, Zita. 1998. Making Instructional Design Decisions. NewJersey: Prentice Hall Inc.

Slavin, Robert E. 2008. Psikologi Pendidikan: Teori dan Praktek. Jakarta: PT. Indeks.

Smaldino, Sharon E. 2008. Instructional Technology and Media for Learning. New Jersey: Pearson Education Ltd.

Soekartawi. 2003. Prinsip Dasar E-Learning: Teori Dan Aplikasinya Di Indonesia. Jurnal Teknodik: Edisi No.12/VII/Oktober/2003.

Youtube. 
